\title{
Mice lacking galectin-3 (Lgals3) function have decreased home cage movement
}

\author{
Tammy R. Chaudoin and Stephen J. Bonasera*
}

\begin{abstract}
Background: Galectins are a large family of proteins evolved to recognize specific carbohydrate moieties. Given the importance of pattern recognition processes for multiple biological tasks, including CNS development and immune recognition, we examined the home cage behavioral phenotype of mice lacking galectin-3 (Lgals3) function. Using a sophisticated monitoring apparatus capable of examining feeding, drinking, and movement at millisecond temporal and $0.5 \mathrm{~cm}$ spatial resolutions, we observed daily behavioral patterns from 10 wildtype male C57BL/6J and $10 \mathrm{Lgals} 3$ constitutive knockout (Lgals3 ${ }^{-1}$; both cohorts aged 2-3 months) mice over 17 consecutive days. We performed a second behavioral assessment of this cohort at age 6-7 months.

Results: At both ages, Lgals3 $3^{-1}$ mice demonstrated less movement compared to wildtype controls. Both forward locomotion and movement-in-place behaviors were decreased in $\mathrm{Lgals}^{-1}{ }^{-1}$ mice, due to decreased bout numbers, initiation rates, and durations. We additionally noted perturbation of behavioral circadian rhythms in $\mathrm{Lgals}^{-1-}$ mice, with mice at both ages demonstrating greater variability in day-to-day performance of feeding, drinking, and movement (as assessed by Lomb-Scargle analysis) compared to wildtype.
\end{abstract}

Conclusion: Carbohydrate recognition tasks performed by Lgals3 may be required for appropriate development of CNS structures involved in the generation and control of locomotor behavior.

Keywords: Circadian rhythm, Galectin-3, Ingestive behavior, Lgals3, Locomotor behavior

\section{Background}

Galectins are an evolutionarily ancient family of proteins sharing a high binding affinity for carbohydrates with $\beta$-galactoside linkages. In the extracellular space, galectins interact (through a conserved carbohydrate recognition domain, aka CRD) with glycosylated proteins to mediate both cell-to-cell interactions and cell-to-matrix adhesion. Galectins are thus pattern recognition molecules specialized to distinguish carbohydrate moieties.

Within the galectin family, galectin-3 (also known as Lgals3) has unique properties. Its preferred ligand is $\mathrm{N}$-acetyllactosamine [1]. It is also the only galectin containing a conserved $\mathrm{N}$-domain as well as a single CRD domain. This $\mathrm{N}$-domain allows Lgals3 not bound to a carbohydrate target to form multimeric complexes [2].

*Correspondence: sbonasera@unmc.edu

Division of Geriatrics, Department of Internal Medicine, University

of Nebraska Medical Center, 3028 Durham Research Center II, Omaha, NE 68198-5039, USA
In this manner, low extracellular Lgals3 concentrations tend to inhibit extracellular interactions and adhesion [3], while high Lgals3 extracellular concentrations facilitate cellular adhesion [4, 5]. Lgals3 affinity for ECM substrates is also modulated by phosphorylation at its Ser6 residue [6].

Lgals3 is an NFKB target gene [7]; Lgals3 protein is widely distributed throughout most tissue sites (as demonstrated by the TiGER Tissue specific gene expression and regulation database; [8]). Furthermore, within specific tissues, Lgals3 protein expression is widespread, with extracellular [9], membrane bound, cytoplasmic, and nuclear localizations (for review, see [10]).

Given these varied Lgals3 tissue and cellular distributions, it is not surprising to find that cellular functions attributed to Lgals3 are numerous and diverse: (1) context-sensitive cell adhesion [11] or dehiscence [12], (2) receptor for advanced glycation (AGE) and advanced lipoxygenation (ALE) end products [13], (3) regulating 
clathrin-independent endocytosis [14], (4) regulating intracellular signal transduction by spacing apart membrane-bound signaling complexes [15], (5) modulating Wnt/ $\beta$-catenin signaling [16], (6) influencing TTF- 1 and STAT transcription factor activities $[17,18],(6)$ regulating mRNA maturation through their effects on spliceosome function [19], (7) repairing DNA damage [20], (8) inducing late $G_{1}$ cell cycle arrest [21], (9) promoting cell proliferation [22], and (10) promoting cell survival through the anti-apoptotic effects of Bcl2 [23]. Lgals3 also participates in immune function. It contributes to innate immunity through its abilities to opsonize cellular debris [24], facilitate generation of respiratory burst enzymes [25], function as a MerTK-specific eat-me signal [26], and act as a CNS alarmin [27]; moreover, it contributes to acquired immunity through its regulation of $\mathrm{T}$ cell activation [15].

Finally, there is an increasing recognition that proteins capable of molecular pattern recognition play significant roles in CNS synapse formation, pruning, and maintenance [28]. Already, many different classes of pattern recognition molecules have been implicated in these processes: major histocompatibility genes [29, 30], complement [31], paired immunoglobulin-like receptors [32], and toll-like receptors [33]. These pattern recognition receptors all have highly conserved glycosylation sites (MHC-I [34]; C3 [35]; PirB [36]; Tlr2 [37]), making them potential Lgals3 interaction partners. Lgals3-mediated recognition of specific $\mathrm{N}$-acetyllactosamine sites may be required for CNS developmental events. For example, prior studies demonstrate that altered Lgals3 expression has a role in age-related synaptic changes accompanying functional loss [38].

\section{Objectives}

We thus assessed baseline behaviors in a mouse model to evaluate Lgals3 influence on important behaviors of clinical interest, including metabolism, feeding, drinking, movement, and circadian rhythm. We measured metabolism using indirect calorimetry with correction for mouse adiposity. We used a sophisticated home cage monitoring approach to assess mouse feeding, drinking, activity, and circadian rhythm in a noninvasive manner over more than 2 weeks of observation. Surprisingly, despite the large number of molecular interactions involving Lgals3, and well-documented Lgals3 CNS expression (in neurons, microglia, and astrocytes), we found only two significant behavioral deficits accompanying constitutive Lgals3 loss: decreased locomotor movement, and diminished fidelity of circadian feeding, drinking, and movement patterns.

\section{Methods}

\section{Ethical statement}

All studies were performed in full concordance with both institutional and federal regulations regarding animal care and use; our research protocol was approved by the University of Nebraska Medical Center (UNMC) Institutional Animal Care and Use Committee (IACUC).

\section{Animal models and husbandry}

We evaluated cohorts of C57BL/6J male mice (stock number 000664) and mice carrying a constitutive Lgals3 mutation (Lgals3 ${ }^{-1-}$; B6.Cg-Lgals3 $3^{\text {tm1Poi } / J ; ~ s t o c k ~ n u m-~}$ ber 006338), both obtained from Jackson Laboratories. Briefly, these mice were created through homologous recombination removing the native Lgals3 exons II, III, and IV and replacing them with a neomycin resistance cassette. Homozygous mutant offspring derived from this targeted lesion expressed only the $3.4 \mathrm{~kb}$ predicted EcoRI fragment, and did not have the $6.4 \mathrm{~kb}$ WT fragment [39]. Mice obtained from Jackson have undergone 7 backcrosses to C57BL/6J from the original chimeric mouse. Upon initial receipt at our vivarium, mice were housed in a microisolator system (Lab Products, Seaford $D E)$ at a density of $\leq 5$ mice per cage. No mice were used for breeding purposes. The facility maintained a 12:12 circadian lighting schedule with lights on at 06:00 CST; vivarium temperatures ranged between 20 and $23{ }^{\circ} \mathrm{C}$. All mice had ad libitum access to food (Envigo Teklad \#7012), water, and environmental enrichment (Crinkle Paper Pouches, WF Fisher). Animal health was checked on a daily basis by UNMC Comparative Medicine staff. Mice remained in the vivarium for 14 days prior to start of testing. While mice were housed in the vivarium, cage bedding, food, and water were changed every 14 days. Mice were returned to the vivarium and kept singlyhoused between the two longitudinal assessments. Following testing, mice were sacrificed by $\mathrm{CO}_{2}$ inhalation followed by cervical dislocation.

\section{Body mass composition}

We performed dual X-ray absorptiometry (DEXA) imaging to measure mouse adiposity. We performed a longitudinal assessment of $10 \mathrm{WT}$ and $10 \mathrm{Lgals}^{-1-}$ mice; we first tested mice at 2-3 months old, followed by repeat assessment at 6-7 months old. Investigators were not blinded to mouse genotype. Mice received DEXA imaging in a random manner. DEXA testing occurred between 10:00 and 16:00. Animals were lightly anesthetized with isoflurane at $1-3$ vol\%, and imaged with a Piximus I (Inside/Outside, Fitchburg WI). Before data acquisition, the system was calibrated by imaging a phantom with 
defined radiological characteristics. We used vendor supplied software (Piximus I, GE Lunar) to identify regions of interest (ROIs) encompassing the mouse chest/abdomen/pelvis for determination of bone mass density (BMD), bone mineral content (BMC), bone area (BArea), tissue area (TArea), ratio of soft tissue attenuation $\left(\mathrm{R}_{\mathrm{ST}}\right)$, total tissue mass (TTM), and percent adiposity (\% fat). Data was analyzed by repeated measures analysis of variance (ANOVA, implemented in MATLAB 2011b) with genotype and mouse age as primary factors, and a genotype $\times$ age interaction.

\section{Indirect calorimetry to assess basal and activity-associated metabolism}

We performed a longitudinal assessment of $10 \mathrm{WT}$ and 10 gals $^{-1-}$ mice; we first tested mice at $2-3$ months old, followed by repeat assessment at 6-7 months old. Investigators were not blinded to mouse genotype. Mice were assigned to calorimetry enclosures in a random manner. Animals were fasted overnight, then placed into 8 hermetically-sealed metabolic cages (Oxymax, Columbus Instruments). Mice were tested between 10:00 and 17:00; each measurement of gas tension required $2 \mathrm{~min}$, so each animal had its metabolic parameters assessed every 16 min during the testing period. We used vendor supplied software (Oxymax for Windows 4.49) to determine maximum oxygen uptake $\left(\dot{\mathrm{VO}}_{2}\right)$, global oxygen delivery $\left(\mathrm{DO}_{2}\right)$, oxygen output $\left(\mathrm{O}_{2}\right.$ out $)$, maximum $\mathrm{CO}_{2}$ production, $\left(\dot{\mathrm{VCO}}_{2}\right)$, global $\mathrm{CO}_{2}$ removal $\left(\mathrm{DCO}_{2}\right), \mathrm{CO}_{2}$ output $\left(\mathrm{CO}_{2}\right.$ out $)$, and heat generated. Basal metabolic rates were determined by averaging measurements obtained during the 3 epochs displaying the least activity (as measured by photobeam brackets spanning the length of the metabolic chamber); similarly, activity-associated metabolic rates were determined by averaging measurements obtained during the 3 epochs displaying the most activity. Metabolic parameters were then adjusted for mouse adiposity and mouse lean body mass using ANCOVA [40, 41]. Full description of our metabolic testing apparatus is provided in [42]. Mice were weighed using a Scout Pro SP401 (Ohaus, Parsippany NJ) before indirect calorimetry, home cage behavioral monitoring, and on a weekly basis between the two longitudinal assessments and following the last assessment.

\section{Home cage behavioral monitoring}

Details describing our home cage behavioral monitoring system have been previously published [43, 44]. Briefly, we measure mouse feeding, drinking, and movement at high temporal and spatial precision in a custom-designed home cage over extended periods of time. Feeding is quantified by the number of times a mouse breaks a photobeam while accessing a food hopper (ms resolution).
Drinking is quantified by a capactive lickometer (ms resolution). Movement is quantified by solving exact equations of torque measured at three load cells and knowing mouse body weight (ms temporal, $0.5 \mathrm{~cm}$ spatial resolution). Data undergoes rigorous automated quality control, followed by behavioral classification and analysis [43]. We performed a longitudinal assessment of $10 \mathrm{WT}$ and $10 \mathrm{Lgals}^{-1-}$ mice; we first tested mice at $2-3$ months old, followed by repeat assessment at 6-7 months old. Mice were randomly assigned to one of 64 home cage behavioral assessment arenas. Each arena contained a niche modeled to approximate dimensions of a mouse burrow to organize mouse resting location, and a nestlet (NES3600, Ancare) for nesting materials. Powdered chow and water were available to all mice ad libitum; behavioral testing room lighting schedule was 12:12 with lights on at $0600 \mathrm{~h}$ CST. Room temperature ranged between 20 and $23{ }^{\circ} \mathrm{C}$; facility relative humidity ranged between 35 and $51 \%$. The arena floor was layered with absorbent bedding (200 $\mathrm{ml}$ Teklad Sani-chips (Envigo, Huntington UK), $300 \mathrm{ml}$ ALPHA-Dri ${ }^{\circledR}+$ PLUS (Shepherd Specialty Papers, Watertown TN)). Mice were allowed to habituate to the home cage monitoring system for 5 days before start of data collection. Investigators were not blinded regarding mouse genotype. We then collected 17 consecutive days of data for each mouse (to ensure that we had at least 14 full days of data after quality control) at each longitudinal assessment time point.

\section{Mouse behavioral data quality control, classification, and analysis}

We employed automated data quality control checks to identify outliers and epochs where there may be questions regarding data integrity (in particular, blocked photobeams and sipper tube leaks). These epochs constituted less than $1 \%$ of total data collected, and were removed from the dataset. Following data quality control, individual mouse feeding, drinking, and movement events were classified to determine active and inactive state properties (in a manner similar to human actigraphy), and to fit these behaviors to a Gaussian mixture model that would allow us to compare bout structures across genotypes. Theory and implementation of these processes has been published in [42, 43 (both manuscript and data supplement), 44].

Following data classification, we performed false-discovery rate (FDR) analysis over 665 different outcomes that assessed differences in major behavioral categories including overall feeding/drinking/movement, time budget, active and inactive state structure, intake and movement bout structure, within-bout structure, and periodicity. These results are provided as Additional file 1: Table 1. For significant behaviors identified by this 
analysis, we quantified genotypic differences in mouse behavior by one-way ANOVA with genotype as primary factor. In these analyses, multiple comparisons were addressed by Bonferroni correction.

\section{Periodicity analysis}

We examined circadian periodicities using Lomb-Scargle analysis, which detects multiple periodicities within a time series $[45,46]$. A major advantage of this approach is that it remains robust in the setting of incompletely sampled data streams. Feeding, drinking, and movement data were binned into 6-min epochs, and significant periodicities (up to $60 \mathrm{~h}$ duration) were calculated using an implementation described by [47] and coded in MATLAB 2011b (MathWorks, Natick MA).

\section{Results}

FDR analysis suggests that $\mathrm{Lgals}^{-1-}$ mice demonstrate significant movement deficits

In $2-3$ months old mice at $\alpha=0.10$, we identified 20 behaviors that significantly differed between the WT and Lgals $3^{-1-}$ cohort, 16 of which related to movement (Additional file 1: Table 1, first tab, column 29). By $x^{2}$ test, movement-related behaviors were overrepresented within this set (16 observed, 7 expected, $p<0.009$ with critical $p<0.016)$. Similarly, in $6-7$ months old mice at $\alpha=0.05$, we identified 82 behaviors that significantly differed between the WT and Lgals ${ }^{-1-}$ cohort, 62 of which were related to movement (Additional file 1: Table 1, second tab, column 29). By $x^{2}$ test, movement-related behaviors were again highly overrepresented within this set (62 observed, 29 expected, $p<1.0 \times 10^{-6}$ with critical $p<0.016)$. These results suggest that $\mathrm{Lgals}^{-1-}$ mice have a deficit in motor function that progresses with age.

\section{Movement deficits in $\mathrm{Lgals}^{-1-}$ mice}

As is evident in Fig. 1a, both $2-3$ months old and 6-7 months old Lgals $^{-1-}$ mice demonstrate significantly less total movement compared to WT mice. This phenotype is particularly prominent during the circadian dark cycle, when mice are most active. In an effort to determine the underlying cause of this decreased movement, we subdivide movement into locomotion (consisting of movements performed at high gait speeds with small turning angles) and movement-in-place (consisting of movements performed at low gait speeds with large turning angles). For 2-3 months old mice, we note no significant genotypic differences in any locomotor bout properties (Fig. 1b, top left). However, for 2-3 months old mice we note significant genotypic differences in movement-in-place bout properties of total movement, bout rate, active state bout rate, bout number, and bout duration (Fig. 1b, top right, also see Table 1). In 2-3 months old Lgals $3^{-1-}$ mice, movement-in-place bouts were also statistically more likely to be the first behavior performed within new dark cycle active states (WT probability $0.09 \pm 0.01 ;$ Lgals $^{-/-}$probability $0.13 \pm 0.01, p<0.007$ with critical $p<0.0125$ ).

The above movement phenotype was more prominent in 6-7 months old mice. We noted genotypic differences in locomotor bout total distance, overall bout rate, active state bout rate, bout number, and bout duration (Fig. 1b bottom left, also Table 2). These differences led to a statistically significant decrease in the percent time devoted to locomotion within a $24 \mathrm{~h}$ time budget $(3.8 \pm 1.0 \% \mathrm{WT}$, $2.5 \pm 0.4 \%$ Lgals $^{-1-}, p<0.002$ with critical $p<0.01$ ). Older Lgals $3^{-1-}$ mice demonstrated changes in movement-in-place bouts similar to those observed in younger mice, with genotypic differences in bout total distance, bout rate, bout active state rate, bout number, and perbout duration (Fig. 1b bottom right, also Table 2). Finally, we again noticed that movement-in-place bouts were statistically overrepresented as the first behavior performed within newly started dark cycle active states (WT probability $0.11 \pm 0.01 ;$ Lgals $^{-/-}$probability $0.18 \pm 0.01$, $p<0.004$ with critical $p<0.0125$ ).

\section{Lgals $3^{-1-}$ mice have greater day-to-day heterogeneity} in circadian rhythms for movement, food, and water intake In both 2-3 months and 6-7 months old mouse cohorts, we note significant decreases in normalized power of the 24-h spectral components for feeding, drinking, and movement behaviors in Lgals $3^{-1-}$ mice (Fig. 2). These decreases suggest an increase in the variability of feeding, drinking, and movement over 6 min time windows extending through the duration of our 16 day long observation. We did not appreciate any significant advance or retreat of the daily activity onset and offset times, nor did we find any statistically significant difference in overall active phase duration.

\section{6-7 months old $\mathrm{Lgals}^{-/-}$mice have greater body weights than WT cohorts}

We found no genotypic differences in neither body weight nor body mass composition between 2 and 3 months old WT and Lgals $3^{-1-}$ mice. Similarly, we found no genotypic differences in basal metabolic or activity-associated metabolic rates between 2 and 3 months old WT and Lgals $3^{-/-}$mice. However, 6-7 months old ggals $^{-1-}$ mice were heavier than their WT counterparts $(27.0 \pm 1.2 \mathrm{~g}$ \left. WT, 28.4 $\pm 1.3{\text { g } \text { Lgals }^{-/-}}^{-} p<0.02\right)$. Body mass over the study time period is shown in Fig. 3, and suggests that the two cohorts diverge around 6-7 months of age. Body mass composition parameters noted with this weight change included greater adiposity $(14.1 \pm 2.1 \%$ WT, $16.1 \pm 2.0 \%$ Lgals $\left.^{-/-}, p<0.03\right)$, greater total tissue 


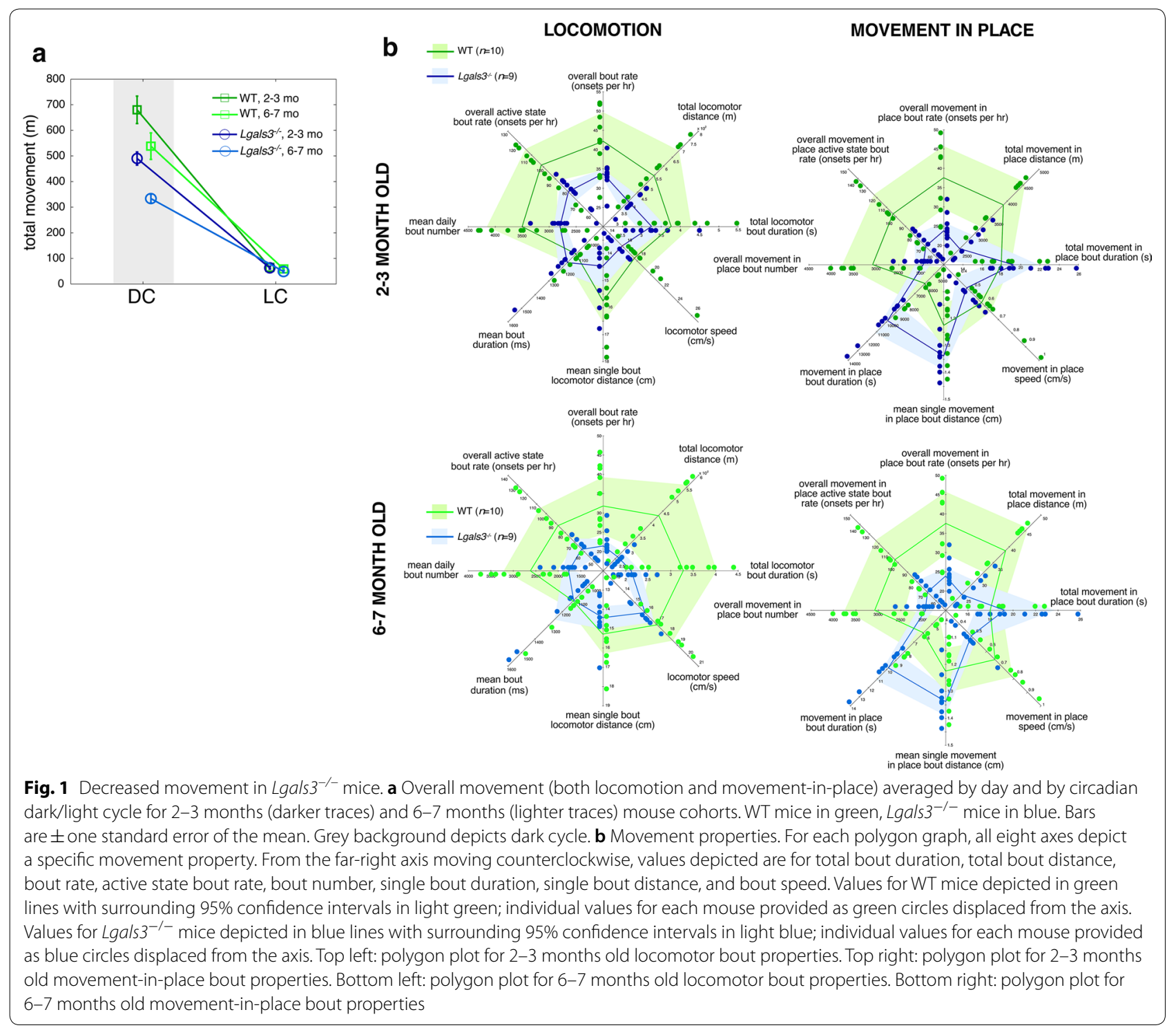

Table 1 Movement bout properties, 2-3 months old cohort

\begin{tabular}{lccc}
\hline Behavior & WT (mean \pm SD) & Lgals3 $^{-/-}($mean \pm SD) & $\boldsymbol{p}$ \\
\hline Movement in place total distance $(\mathrm{m})$ & $43.8 \pm 7.6$ & $26.9 \pm 3.7$ & $<0.02$ \\
Movement in place bout rate (onsets/h) & $45.0 \pm 9.1$ & $24.7 \pm 3.8$ & $<0.02$ \\
Movement in place bout active rate & $106.0 \pm 20.2$ & $68.6 \pm 11.0$ & $<0.01$ \\
Movement in place total number bouts & $3736 \pm 758$ & $2031 \pm 308$ & $<0.02$ \\
Movement in place mean bout duration $(\mathrm{s})$ & $6.5 \pm 1.7$ & $10.1 \pm 1.4$ & $<0.01$ \\
\hline
\end{tabular}

mass $\left(23.8 \pm 1.0 \mathrm{~g} \mathrm{WT}, 25.3 \pm 1.3 \mathrm{~g} \mathrm{Lgals}^{-/-}, p<0.01\right)$, and greater bone mineral density $(0.051 \pm 0.003 \mathrm{OD} /$ $\mathrm{cm}^{2} \mathrm{WT}, 0.0054 \pm 0.002 \mathrm{OD} / \mathrm{cm}^{2}$ Lgals $\left.^{-1-}, p<0.008\right)$ in 6-7 months old Lgals $3^{-1-}$ compared to WT mice. No differences in either basal or activity-associated metabolic rates were appreciated between 6 and 7 months old WT and ggals $^{-1-}$ mice. 
Table 2 Movement bout properties, 6-7 months old cohort

\begin{tabular}{|c|c|c|c|}
\hline Behavior & $\mathrm{WT}($ mean $\pm \mathrm{SD})$ & Lgals3 $^{-I-}($ mean $\pm S D)$ & $p$ \\
\hline Locomotor total distance (m) & $422.9 \pm 135.5$ & $261.5 \pm 29.3$ & $<0.003$ \\
\hline Locomotor bout rate (onsets/h) & $33.2 \pm 8.6$ & $22.2 \pm 3.5$ & $<0.002$ \\
\hline Locomotor bout active state rate & $90.5 \pm 23.9$ & $61.5 \pm 11.0$ & $<0.004$ \\
\hline Locomotor total number bouts & $2726 \pm 704$ & $1821 \pm 289.6$ & $<0.002$ \\
\hline Locomotor total bout duration (s) & $3123.5 \pm 833.3$ & $2123.4 \pm 306.1$ & $<0.004$ \\
\hline Movement in place total distance $(\mathrm{m})$ & $37.3 \pm 8.5$ & $26.9 \pm 4.5$ & $<0.004$ \\
\hline Movement in place bout rate (onsets/h) & $37.0 \pm 9.2$ & $24.7 \pm 3.6$ & $<0.002$ \\
\hline Movement in place bout active rate & $100.5 \pm 24.9$ & $68.6 \pm 11.8$ & $<0.003$ \\
\hline Movement in place total number bouts & $3032 \pm 759$ & $2031 \pm 298$ & $<0.002$ \\
\hline Movement in place mean bout duration (s) & $6.4 \pm 1.8$ & $10.1 \pm 2.0$ & $<0.0006$ \\
\hline
\end{tabular}

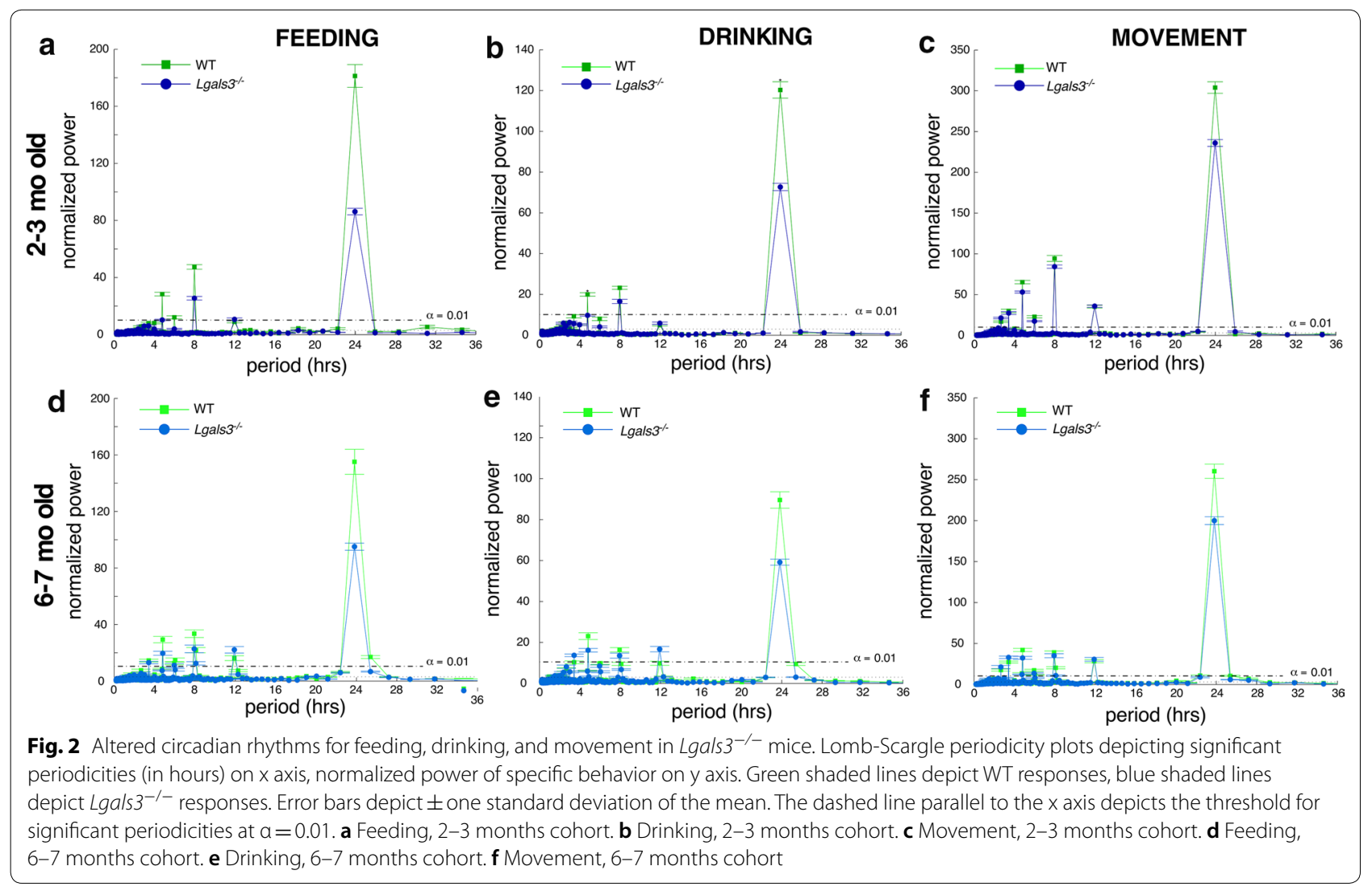

Phenotypes with no difference between WT and Lgals $^{-/-}$ cohorts in both 2-3 and 6-7 months old mice

Regarding home cage phenotypes, we noted no significant differences in overall food or water ingestion between WT and Lgals $3^{-1-}$ mice. Except for the previously-noted difference in time allocated to locomotion seen across the 6-7 month old cohorts, there were no significant differences in the $24 \mathrm{~h}$ time budgets for feeding, drinking, locomotion, movement-in-place, and resting. There were also no differences in the percentage of time within an active state devoted to feeding, drinking, locomotion, and movement-in-place. We noted no significant differences (overall, or in either circadian dark or light cycles) in active or inactive state properties, including state onset rates, state durations, state transition probabilities, and total numbers of states. Finally, we 


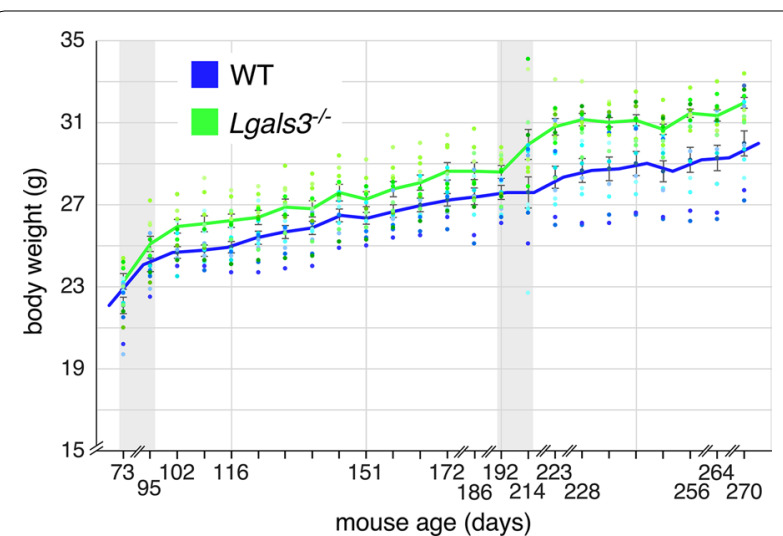

Fig. 3 Mouse body mass versus time. Lines depict mean body weights for WT (blue) and Lgals $3^{-/-}$(green) mice; error bars are \pm one standard error of the mean. Scattergrams for individual mice are depicted by small filled circles. Circles in shades of blue correspond to WT mice; circles in shades of green correspond to $\mathrm{Lgals}^{-/-}$mice.

Grey bands depict periods where mouse cohorts were tested in the home cage monitoring system. Note that neither axis begins at 0 . Sampling interval for $x$-axis is 7 days except where noted by breakpoints

noted no differences in bout properties of feeding and drinking, including the circadian patterns of total bout intake, bout onset, bout probability, bout duration, bout intensity, and per-bout intake.

\section{Discussion}

There are currently few published studies examining the behavioral consequences of Lgals3 loss. The Consortium for Functional Glycomics (CFG) spearheaded an impressive effort to obtain baseline behavioral profiles for a wide variety of genes involved in carbohydrate biology, including Lgals3. Their results suggested that Lgals $3^{-/-}$mice had diminished freezing in a contextual fear assay, and were more aggressive both in response to an approaching object and in a paired social encounter [48, 49]. Lgals3 has also been implicated in regulation of energy balance status and development of obesity [50]. Loss of Lgals3 function was associated with accelerated development of obesity, increased adiposity, insulin resistance, metabolic syndrome, and type II diabetes in mice receiving a high fat diet ([51, 52]; however, data from [53, 54] suggest low Lgals3 expression as potentially protective against type II DM). Lgals3 also has been shown to regulate adipose tissue development and function [55-57], and may be an important molecule mediating how diet influences hepatic steatosis $[58,59]$. Finally, impaired cognition in older adults has been associated with specific Lgals3 polymorphisms (rs4644, rs4652, and rs1009977; [60]).

Comparing the above studies to our work, we first note that the CFG investigators observed no genotypic differences in body weight, dark and light cycle metabolic rates, and locomotion. Similarly, we did not find any genotypic differences in food consumption or basal/activityassociated metabolic rates in either 2-3 months old or 6-7 months old mouse cohorts. Values for $\dot{\mathrm{VO}}_{2}$ reported by CFG for both light and dark cycle epochs were consistent with our measured basal and activity-associated $\dot{\mathrm{VO}}_{2}$. We also noted no genotypic differences in body weight between 2 and 3 months WT and Lgals $3^{-1-}$ mice. However, 6-7 months old mice (slightly older than the oldest reported in [48]) had increased body weight and greater adiposity in Lgals $3^{-1-}$ compared to WT cohorts. Since the Teklad 7012 diet is $17 \%$ fat, and mouse dietary requirements are estimated at $5 \%$ fat [61], it is reasonable to suggest that the increase in $\operatorname{Lgals} 3^{-/-}$body weight/ adiposity we observe in part replicates prior findings of high-fat-diet-induced obesity.

We provide the first data suggesting Lgals3 involvement in motor system development and/or performance. Specifically, we noted an overall $\sim 30 \%$ decrease in gals $^{-1-}$ movement (both locomotion and movement in place) compared to WT mice. This decrease was observed in an acclimated home cage over 16 days, and thus does not assess the same construct reported by the CFG investigators, who found no change in open field locomotion over 30 min. Lgals $3^{-1-}$ mice therefore display decreased home cage locomotion with no change in novelty-evoked locomotion. The moderate increase in $\operatorname{Lgals} 3^{-1-}$ body weight may slightly increase the behavioral cost of movement, and thus decrease total movement. However, the prominent differences in movement-in-place bout rate, active state bout rate, bout duration, and bout number observed in 2-3 months old mice, as well as the large differences in both locomotion and movement-in-place bout rate, active state bout rate, bout duration, and bout number observed in 6-7 months old mice, suggest that Lgals3 constitutive loss evokes functional deficits in underlying motor substrates. Both gene (ebi.ac.uk/gxa, informatics.jax.org/expression.shtml) and protein expression (emouseatlas.org, proteinatlas.org) atlases suggest that Lgals3 expression (at low-to-moderate levels) occurs in both pre-and post-natal brain, and has been localized to regions involved in motor behavior generation, including the cortex, striatum, cerebellum, and spinal cord. We thus argue that Lgals3 loss alters mouse motor function, either through its impact on motor development or through altered neuronal signaling in CNS regions that regulate or produce motor behavior. Further studies examining the consequences of Lgals3 loss at synaptic, neuronal, ensemble, and tissue levels of organization will be required to determine the precise mechanisms underlying this functional loss. 
As mentioned earlier, Lgals3 has been implicated in a large number of physiological tasks at both a cellular and organwide level of organization. It is thus notable that mice with complete loss of Lgals3 function demonstrate relatively few behavioral differences when compared to wildtype C57BL/6J mice. This finding suggests that, at least in the mouse, there is some genetic redundancy regarding Lgals3 function. Studies of galectin evolution focusing on intron/exon organization as well as sequence identity suggest that duplication of ancestral galectin genes in animal lineages preceding the first teleost fish [62] provided the precursors for what has become a large vertebrate protein family [63]. There is also data suggesting that galectins may be able to substitute for one another in specific circumstances. For example, Lgals1 may compensate for Lgals3 loss at the spliceosome [64]. Extracellular Lgals1 also regulates $\mathrm{T}$ cell apoptosis in a manner similar to that of extracellular Lgals3 [65]. The behavioral phenotype arising from Lgals3 functional loss thus identifies neuronal loci and processes where there is no compensation for gene loss.

Finally, these findings support the hypothesis that loss of molecules with specific pattern recognition properties (in this case, for $\beta$-galactosidase linkages) evokes behavioral phenotypes potentially arising from inappropriate neuronal synaptogenesis, pruning, and/or maintenance. There is already clear evidence that molecules able to recognize specific protein regions play crucial roles during CNS development $[66,67]$. This study further implies that molecules able to recognize specific carbohydrate regions may have parallel roles during CNS development. Further efforts to understand carbohydrate recognition in the developing brain are thus clearly justified, and may provide important and clinically relevant insights into significant psychiatric conditions, including autism spectrum disorders [68] and schizophrenia [69].

\section{Conclusions}

This study provides the first data describing home cage feeding, drinking, movement, and circadian rhythm in mice cohorts constitutively lacking Lgals3 function. We performed a longitudinal assay of these behaviors at 2-3 and 6-7 months of age. At both ages, Lgals $^{-1-}$ mice showed less home cage movement compared to WT. This decrease was due to decreases in both forward locomotion and movement-in-place. These differences grew more pronounced with age. In older mice, we could further determine that decreased movement was a result of lower bout initiation rates (for both locomotor and movement-in-place bouts), with similar distances traversed per bout. Lower bout initiation rates also led to lower total numbers of locomotion and movement-in place bouts. Lgals ${ }^{-/-}$mice at both ages also had more heterogeneous circadian patterns of feeding, drinking, and movement compared to WT mice.

\section{Additional file}

Additional file 1: Table 1. Lgals $3^{-/-}$and WT behavioral metrics. Column 1 lists the abbreviation for each behavior, Column 2 lists the overall behavioral assay class, Column 3 provides a brief description of the behavior, Column 4 is an index. Columns 5 and Column 6 list mean values for each behavior, control and Lgals $3^{-1-}$ respectively. Columns $7-25$ list results for each test by individual mouse. Control mice are listed in columns 7-16; Lgals3 ${ }^{-1-}$ mice are listed in columns 17-25. Columns 26, 28, and 30 provide unadjusted $p$ values calculated by Mann-Whitney, Student's $t$ test, and fold change (B) methods. Columns 27 and 29 provide $p$ values adjusted by false discovery rate (FDR) for Mann-Whitney (column 27) and Student's $t$ test (column 29). Column 31 lists the behavioral fold change. Labeled spreadsheet tabs correspond to 2-3 months old and 6-7 month old cohorts, respectively.

\section{Abbreviations}

Lgals3: galectin-3; CRD: carbohydrate recognition domain; DEXA: dual energy X-ray absorptiometry; BMD: bone mass density; BMC: bone mineral content; BArea: bone area; TArea: tissue area; $\mathrm{R}_{\mathrm{ST}}$ : ratio of soft tissue attenuation; TTM: total tissue mass; $\mathrm{VO}_{2}$ : maximum oxygen uptake; $\mathrm{DO}_{2}$ : global oxygen delivery; $\mathrm{O}_{2}$ out: oxygen output; $\mathrm{VCO}_{2}$ : maximum $\mathrm{CO}_{2}$ production; $\mathrm{DCO}_{2}$ : global $\mathrm{CO}_{2}$ removal; $\mathrm{CO}_{2}$ out: $\mathrm{CO}_{2}$ output; FDR: false discovery rate; WT: wildtype.

\section{Authors' contributions}

TRC performed experiments, data analysis, manuscript preparation; SJB performed data analysis, manuscript preparation. Both authors have read and approved the final manuscript.

\section{Acknowledgements \\ We thank Carol A. Casey, Ph.D. and Nicholas W. DeKorver, Ph.D. for their critique of earlier versions of this manuscript.}

\section{Competing interests}

The authors declare that they have no competing interests.

\section{Consent for publication}

Not applicable.

\section{Availability of data and materials}

The datasets generated and/or analyzed during the current study are available in the University of Nebraska Digital Commons repository (http://digitalcom mons.unmc.edu/geriatrics_data/4/).

\section{Ethics approval}

All studies were performed in full concordance with both institutional and federal regulations regarding animal care and use; our research protocol was approved by the University of Nebraska Medical Center (UNMC) Institutional Animal Care and Use Committee (IACUC). Our protocol reference number is 17-060-08.

\section{Funding}

This work was supported by the National Institutes of Health/National Institute on Aging (AG031158 to SJB).

\section{Publisher's Note}

Springer Nature remains neutral with regard to jurisdictional claims in published maps and institutional affiliations. 
Received: 17 November 2017 Accepted: 21 April 2018

Published online: 02 May 2018

\section{References}

1. Agrwal N, Sun Q, Wang SY, Wang JL. Carbohydrate-binding protein 35. I. Properties of the recombinant polypeptide and the individuality of the domains. J Biol Chem. 1993:268(20):14932-9.

2. Massa SM, Cooper DN, Leffler H, Barondes SH. L-29, an endogenous lectin, binds to glycoconjugate ligands with positive cooperativity. Biochemistry. 1993;32(1):260-7.

3. Song S, Mazurek N, Liu C, Sun Y, Ding QQ, Liu K, Hung MC, Bresalier RS. Galectin-3 mediates nuclear $\beta$-catenin accumulation and Wnt signaling in human colon cancer cells by regulation of glycogen synthase kinase-3 $\beta$ activity. Can Res. 2009;69(4):1343-9.

4. Hughes RC. Galectins as modulators of cell adhesion. Biochimie. 2001:83:667-76

5. Matarrese P, Fusco O, Tinari N, Natoli C, Liu FT, Semeraro ML, Malorni W, lacobelli S. Galectin-3 overexpression protects from apoptosis by improving cell adhesion properties. Int J Cancer. 2000;85(4):545-54.

6. Mazurek N, Conklin J, Byrd JC, Raz A, Bresalier RS. Phosphorylation of the $\beta$-galactoside-binding protein galectin-3 modulates binding to its ligands. J Biol Chem. 2000:275(46):36311-5.

7. Hsu DK, Hammes SR, Kuwabara I, Greene WC, Liu FT. Human T lymphotropic virus-I infection of human T lymphocytes induces expression of the beta-galactoside-binding lectin, galectin-3. Am J Pathol. 1996;148(5):1661-70.

8. Liu X, Yu X, Zack DJ, Zhu H, Qian J. TiGER: a database for tissue-specific gene expression and regulation. BMC Bioinform. 2008;9:271.

9. Cherayil BJ, Chaitovitz S, Wong C, Pillai S. Molecular cloning of a human macrophage lectin specific for galactose. Proc Natl Acad Sci USA. 1990:87(18):7324-8.

10. Haudek KC, Spronk KJ, Voss PG, Patterson RJ, Wang JL, Arnoys EJ. Dynamics of galectin-3 in the nucleus and cytoplasm. Biochim Biophys Acta (BBA) Gener Subj. 2010;1800(2):181-9.

11. Friedrichs J, Torkko JM, Helenius J, Teräväinen TP, Füllekrug J, Muller DJ Simons K, Manninen A. Contributions of galectin-3 and-9 to epithelial cell adhesion analyzed by single cell force spectroscopy. J Biol Chem. 2007;282(40):29375-83.

12. Friedrichs J, Manninen A, Muller DJ, Helenius J. Galectin-3 regulates integrin a2 31 -mediated adhesion to collagen-I and-IV. J Biol Chem. 2008;283(47):32264-72.

13. Pricci F, Leto G, Amadio L, lacobini C, Romeo G, Cordone S, Gradini R, Barsotti P, Liu FT, Di Mario U, Pugliese G. Role of galectin-3 as a receptor for advanced glycosylation end products. Kidney Int. 2000:58:S31-9.

14. Lakshminarayan R, Wunder C, Becken U, Howes MT, Benzing C, Arumugam S, Sales S, Ariotti N, Chambon V, Lamaze C, Loew D. Galectin-3 drives glycosphingolipid-dependent biogenesis of clathrin-independent carriers. Nat Cell Biol. 2014;16(6):592-603.

15. Demetriou M, Granovsky M, Quaggin S, Dennis JW. Negative regulation of T-cell activation and autoimmunity by Mgat5N-glycosylation. Nature. 2001:409(6821):733-9.

16. Shimura T, Takenaka Y, Tsutsumi S, Hogan V, Kikuchi A, Raz A. Galectin-3, a novel binding partner of $\beta$-catenin. Can Res. 2004;64(18):6363-7.

17. Paron I, Scaloni A, Pines A, Bachi A, Liu FT, Puppin C, Pandolfi M, Ledda L, Di Loreto C, Damante G, Tell G. Nuclear localization of Galectin-3 in transformed thyroid cells: a role in transcriptional regulation. Biochem Biophys Res Commun. 2003;302(3):545-53.

18. Jeon SB, Yoon HJ, Chang CY, Koh HS, Jeon SH, Park EJ. Galectin-3 exerts cytokine-like regulatory actions through the JAK-STAT pathway. J Immunol. 2010;185(11):7037-46.

19. Dagher SF, Wang JL, Patterson RJ. Identification of galectin-3 as a factor in pre-mRNA splicing. Proc Natl Acad Sci USA. 1995;92(4):1213-7.

20. Carvalho RS, Fernandes VC, Nepomuceno TC, Rodrigues DC, Woods NT, Suarez-Kurtz G, Chammas R, Monteiro AN, Carvalho MA. Characterization of LGALS3 (galectin-3) as a player in DNA damage response. Cancer Biol Ther. 2014:15(7):840-50

21. Kim HR, Lin HM, Biliran H, Raz A. Cell cycle arrest and inhibition of anoikis by galectin-3 in human breast epithelial cells. Can Res. 1999;59(16):4148-54
22. Inohara H, Akahani S, Raz A. Galectin-3 stimulates cell proliferation. Exp Cell Res. 1998;245(2):294-302.

23. Yang RY, Hsu DK. Llu FT. Expression of galectin-3 modulates T-cell growth and apoptosis. Proc Natl Acad Sci USA. 1996;93(13):6737-42.

24. Karlsson A, Christenson K, Matlak M, Björstad Å, Brown KL, Telemo E, Salomonsson E, Leffler H, Bylund J. Galectin-3 functions as an opsonin and enhances the macrophage clearance of apoptotic neutrophils. Glycobiology. 2008;19(1):16-20.

25. Yamaoka A, Kuwabara I, Frigeri LG, Liu FT. A human lectin, galectin-3 (epsilon bp/Mac-2), stimulates superoxide production by neutrophils. J Immunol. 1995;154(7):3479-87.

26. Caberoy NB, Alvarado G, Bigcas JL, Li W. Galectin-3 is a new MerTK-specific eat-me signal. J Cell Physiol. 2012;227(2):401-7.

27. Yip PK, Carrillo-Jimenez A, King P, Vilalta A, Nomura K, Chau CC, Egerton AM, Liu ZH, Shetty AJ, Tremoleda JL, Davies M. Galectin-3 released in response to traumatic brain injury acts as an alarmin orchestrating brain immune response and promoting neurodegeneration. Sci Rep. 2017:7:41689.

28. Schafer DP, Stevens B. Synapse elimination during development and disease: immune molecules take centre stage. Biochem Soc Trans. 2010;38(2):476-81.

29. Huh GS, Boulanger LM, Du H, Riquelme PA, Brotz TM, Shatz CJ. Functional requirement for class I MHC in CNS development and plasticity. Science. 2000;290(5499):2155-9.

30. Glynn MW, Elmer BM, Garay PA, Liu XB, Needleman LA, El-Sabeawy F, McAllister AK. $\mathrm{MHCl}$ negatively regulates synapse density during the establishment of cortical connections. Nat Neurosci. 2011;14(4):442-51.

31. Stevens B, Allen NJ, Vazquez LE, Howell GR, Christopherson KS, Nouri N, Micheva KD, Mehalow AK, Huberman AD, Stafford B, Sher A, Litke AM, Lambris JD, Smith SJ, John SWM, Barres BA. The classical complement cascade mediates CNS synapse elimination. Cell. 2007;131(6):1164-78.

32. Djurisic M, Vidal GS, Mann M, Aharon A, Kim T, Santos AF, Zuo Y, Hübener $M$, Shatz CJ. PirB regulates a structural substrate for cortical plasticity. Proc Natl Acad Sci USA. 2013;110(51):20771-6.

33. DeKorver NW, Chaudoin TR, Bonasera SJ. Toll-like receptor 2 is a regulator of circadian active and inactive state consolidation in C57BL/6 mice. Front Aging Neurosci. 2017;9:219.

34. Ryan SO, Cobb BA. Roles for major histocompatibility complex glycosylation in immune function. In: Lowe J, editor. Seminars in immunopathology 2012 May 1, Vol. 34, No. 3. Berlin: Springer, p. 425-441. https://link. springer.com/journal/281/34/3/page/1

35. Janssen BJ, Halff EF, Lambris JD, Gros P. Structure of compstatin in complex with complement component $\mathrm{C} 3 \mathrm{C}$ reveals a new mechanism of complement inhibition. J Biol Chem. 2007;282(40):29241-7.

36. Hayami K, Fukuta D, Nishikawa Y, Yamashita Y, Inui M, Ohyama Y, Hikida $\mathrm{M}$, Ohmori $\mathrm{H}$, Takai T. Molecular cloning of a novel murine cell-surface glycoprotein homologous to killer cell inhibitory receptors. J Biol Chem. 1997;272(11):7320-7

37. Weber AN, Morse MA, Gay NJ. Four N-linked glycosylation sites in human toll-like receptor 2 cooperate to direct efficient biosynthesis and secretion. J Biol Chem. 2004;279(33):34589-94.

38. Bonasera SJ, Arikkath J, Boska MD, Chaudoin TR, DeKorver NW, Goulding EH, Hoke TA, Mojtahedzedah V, Reyelts CD, Sajja B, Schenk AK. Agerelated changes in cerebellar and hypothalamic function accompany non-microglial immune gene expression, altered synapse organization, and excitatory amino acid neurotransmission deficits. Aging (Albany NY). 2016:8(9):2153

39. Colnot C, Fowlis D, Ripoche MA, Bouchaert I, Poirier F. Embryonic implantation in galectin 1/galectin 3 double mutant mice. Dev Dyn. 1998:211(4):306-13.

40. Tschöp MH, Speakman JR, Arch JR, Auwerx J, Brüning JC, Chan L, Eckel RH, Farese RV Jr, Galgani JE, Hambly C, Herman MA. A guide to analysis of mouse energy metabolism. Nat Methods. 2012;9(1):57-63.

41. Even PC, Nadkarni NA. Indirect calorimetry in laboratory mice and rats: principles, practical considerations, interpretation and perspectives. Am J Physiol Regul Integr Comp Physiol. 2012;303(5):R459-76.

42. Bonasera SJ, Chaudoin TR, Goulding EH, Mittek M, Dunaevsky A. Decreased home cage movement and oromotor impairments in adult Fmr1-KO mice. Genes Brain Behav. 2017;16(5):564-73. 
43. Goulding EH, Schenk AK, Juneja P, MacKay AW, Wade JM, Tecott LH. A robust automated system elucidates mouse home cage behavioral structure. Proc Natl Acad Sci USA. 2008;105(52):20575-82.

44. Parkison SA, Carlson JD, Chaudoin TR, Hoke TA, Schenk AK, Goulding EH, Pérez LC, Bonasera SJ. A low-cost, reliable, high-throughput system for rodent behavioral phenotyping in a home cage environment. In: 2012 annual international conference of the IEEE on engineering in medicine and biology society (EMBC), IEEE, p. 2392-2395.

45. Lomb NR. Least-squares frequency analysis of unequally spaced data. Astrophys Space Sci. 1976;39(2):447-62.

46. Scargle JD. Studies in astronomical time series analysis. II-Statistical aspects of spectral analysis of unevenly spaced data. Astrophys $\mathrm{J}$. 1982:263:835-53.

47. Van Dongen HP, Olofsen E, Van Hartevelt JH, Kruyt EW. A procedure of multiple period searching in unequally spaced time-series with the Lomb-Scargle method. Biol Rhythm Res. 1999;30(2):149-77.

48. Orr SL, Le D, Long JM, Sobieszczuk P, Ma B, Tian H, Fang X, Paulson JC, Marth JD, Varki N. A phenotype survey of 36 mutant mouse strains with gene-targeted defects in glycosyltransferases or glycan-binding proteins. Glycobiology. 2012;23(3):363-80.

49. www.functionalglycomics.org:80/glycomics/behavior/jsp/searchBeha viorResults.jsp?searchType $=0 \&$ expld $=\% 25 \&$ criteria $0=i$ s\&searchResu ItsType $=$ download\&criteria2=is\&targetGene $=$ Gal-3\&sideMenu=no. Accessed 17 April 2018

50. Menini S, lacobini C, Blasetti Fantauzzi C, Pesce CM, Pugliese G. Role of galectin-3 in obesity and impaired glucose homeostasis. Oxid Med Cell Longev. 2016;2016:9618092.

51. Pejnovic NN, Pantic JM, Jovanovic IP, Radosavljevic GD, Milovanovic MZ, Nikolic IG, Zdravkovic NS, Djukic AL, Arsenijevic NN, Lukic ML. Galectin-3 deficiency accelerates high-fat diet-induced obesity and amplifies inflammation in adipose tissue and pancreatic islets. Diabetes. 2013;62(6):1932-44.

52. Pang J, Rhodes DH, Pini M, Akasheh RT, Castellanos KJ, Cabay RJ, Cooper D, Perretti M, Fantuzzi G. Increased adiposity, dysregulated glucose metabolism and systemic inflammation in Galectin-3 KO mice. PLoS ONE. 2013;8(2):e57915

53. Saksida T, Nikolic I, Vujicic M, Nilsson UJ, Leffler H, Lukic ML, Stojanovic I, Stosic-Grujicic S. Galectin-3 deficiency protects pancreatic islet cells from cytokine-triggered apoptosis in vitro. J Cell Physiol. 2017;228(7):1568-76.

54. Yilmaz H, Cakmak M, Inan O, Darcin T, Akcay A. Increased levels of galectin-3 were associated with prediabetes and diabetes: new risk factor? J Endocrinol Invest. 2015;38(5):527-33.

55. Kiwaki K, Novak CM, Hsu DK, Liu FT, Levine JA. Galectin-3 stimulates preadipocyte proliferation and is up-regulated in growing adipose tissue. Obesity. 2007;15(1):32-9.
56. Rhodes DH, Pini M, Castellanos KJ, Montero-Melendez T, Cooper D, Perretti M, Fantuzzi G. Adipose tissue-specific modulation of galectin expression in lean and obese mice: evidence for regulatory function. Obesity. 2013;21(2):310-9.

57. Baek JH, Kim SJ, Kang HG, Lee HW, Kim JH, Hwang KA, Song J, Chun KH. Galectin-3 activates PPARY and supports white adipose tissue formation and high-fat diet-induced obesity. Endocrinology. 2015;156(1):147-56.

58. Pejnovic N, Jeftic I, Jovicic N, Arsenijevic N, Lukic ML. Galectin-3 and IL-33/ST2 axis roles and interplay in diet-induced steatohepatitis. World J Gastroenterol. 2016;22(44):9706.

59. Jeftic I, Jovicic N, Pantic J, Arsenijevic N, Lukic ML, Pejnovic N. Galectin-3 ablation enhances liver steatosis, but attenuates inflammation and IL-33-dependent fibrosis in obesogenic mouse model of nonalcoholic steatohepatitis. Mol Med. 2015;21(1):453.

60. Trompet S, Jukema W, Mooijaart SP, Ford I, Stott DJ, Westendorp RG, de Craen AJ. Genetic variation in galectin-3 gene associates with cognitive function at old age. Neurobiol Aging. 2012;33(9):2232-e1.

61. Reeves PG, Shaw HA, Smith JE, Steele RD. Nutrient requirements of the mouse. From: Nutrient requirements of laboratory animals. 4th ed. Washington: National Academies Press; 1995.

62. Houzelstein D, Gonçalves IR, Fadden AJ, Sidhu SS, Cooper DN, Drickamer $\mathrm{K}$, Leffler $\mathrm{H}$, Poirier F. Phylogenetic analysis of the vertebrate galectin family. Mol Biol Evol. 2004;21(7):1177-87.

63. Cooper DN, Barondes SH. God must love galectins; He made so many of them. Glycobiology. 1999;9(10):979-84.

64. Patterson RJ, Wang W, Wang JL. Understanding the biochemical activities of galectin-1 and galectin-3 in the nucleus. Glycoconj J. 2002;19(7):499-506

65. Stillman BN, Hsu DK, Pang M, Brewer CF, Johnson P, Liu FT, Baum LG Galectin-3 and galectin-1 bind distinct cell surface glycoprotein receptors to induce T cell death. J Immunol. 2006;176(2):778-89.

66. Cebrián C, Loike JD, Sulzer D. Neuronal MHC-l expression and its implications in synaptic function, axonal regeneration and Parkinson's and other brain diseases. Front Neuroanat. 2014;8:114

67. Zabel MK, Kirsch WM. From development to dysfunction: microglia and the complement cascade in CNS homeostasis. Ageing Res Rev. 2013;12(3):749-56.

68. Bauman ML, Kemper TL. Neuroanatomic observations of the brain in autism: a review and future directions. Int J Dev Neurosci. 2005;23(2):183-7.

69. Nimgaonkar VL, Prasad KM, Chowdari KV, Severance EG, Yolken RH. The complement system: a gateway to gene-environment interactions in schizophrenia pathogenesis. Mol Psychiatry. 2017;22:1554.
Ready to submit your research? Choose BMC and benefit from:

- fast, convenient online submission

- thorough peer review by experienced researchers in your field

- rapid publication on acceptance

- support for research data, including large and complex data types

- gold Open Access which fosters wider collaboration and increased citations

- maximum visibility for your research: over $100 \mathrm{M}$ website views per year

At $\mathrm{BMC}$, research is always in progress.

Learn more biomedcentral.com/submissions 